\title{
PERSPECTIVA AFROCENTRADA NAS CONTAÇÕES DE HISTÓRIA NA BRINQUEDOTECA DO CAFS: FORTALECIMENTO DA AUTOESTIMA E IDENTIDADE NEGRA DE CRIANÇAS
}

\author{
Paulo de Tarso da Silva Júnior \\ Aluno do Curso de Pedagogia e monitor-brinquedista \\ do Campus Amílcar Ferreira Sobral UFPI \\ paratarsotapety@gmail.com \\ Carla Andréa Silva \\ Professora coordenadora do Curso de Pedagogia \\ do Campus Amílcar Ferreira Sobral
}

Fecha de Recepción: 5 Febrero 2019

Fecha de Admisión: 30 Abril 2019

\section{RESUMO}

A brinquedoteca em questão é um espaço aberto à comunidade local, atendendo crianças de escolas da Educação Infantil e anos iniciais do Ensino Fundamental, bem como graduandos, proporcionando momentos lúdicos nos quais se estimula a leitura, a brincadeira, dramatizar, expressarse e experimentar diferentes tipos de jogos e brincadeiras, bem como outras atividades de caráter pedagógico, lúdico e cultural relacionadas à temática da infância. Nas ações de pesquisa, extensão e formação dos alunos que atuam como monitores-brinquedistas, o referencial teórico de suporte tem sido a perspectiva histórico-cultural. Na extensão, emergiu do plano de trabalho intitulado "Contação e dramatização de histórias infantis" o interesse em trabalhar a atividade de contação de histórias voltadas para o debate das relações etnorraciais na Educação Infantil, nascendo daí o plano de trabalho "Pretagogia: a contação de história na perspectiva etnorracial nas atividades da Brinquedoteca do CAFS". Fundamentou-se na Lei 10.639/03 bem como nas produções de autores brasileiros e estrangeiros relacionados ao tema ora investigado. Como resultados, confirmou-se que a prática de contar histórias é essencial para a formação da criança, ao promover situações direcionadas a integração destas com a sociedade bem como a transformação do seu mundo interior.

Palavras-chave: brinquedoteca; contação de histórias; pretagogia; relações etnorraciais

\section{ABSTRACT}

Perspectiva afrocentrada nas contações de história na brinquedoteca do cafs: fortalecimento da autoestima e identidade negra de crianças. The toy library in question is a space open to the local community, attending children from elementary school and early years of elementary school 


\section{PERSPECTIVA AFROCENTRADA NAS CONTAÇ̃̃ES DE HISTÓRIA NA BRINQUEDOTECA DO CAFS: FORTALECIMENTO DA AUTOESTIMA E IDENTIDADE NEGRA DE CRIANÇAS}

as well as undergraduates, providing playful moments in which it stimulates to read, play, dramatize, express themselves, try different types of games and games, as well as other activities of a pedagogical, playful and cultural nature related to the theme of childhood. In the actions of research, extension and training of students who act as monitors-toys, the theoretical support framework has been the cultural historical perspective. In extension, emerged from the work plan titled "Contamination and dramatization of children's stories" the interest in working the activity of storytelling focused on the debate of ethnoracial relations in Early Childhood Education, hence the work plan, Pretagogia: the counting of history in the ethnorcial perspective in the activities of CAFS Toy Library. It was based on Law 10.639 / 03 , as well in national and foreign studies related with the subject. As a result, it was confirmed that the practice of storytelling is essential for the formation of the child, in promoting situations, in the sense of integration with society and transformation of his inner world.

Keywords: toy library; storytelling; pretagogia; ethnic-racial relations

\section{INTRODUÇÃO}

Este trabalho objetiva apresentar as experiências de extensão vividas por alunos-brinquedistas do curso de licenciatura em Pedagogia, da Universidade Federal do Piauí, Campus Amílcar Ferreira Sobral. As atividades aqui relatadas foram propostas pela Brinquedoteca da instituição, oriunda do Projeto intitulado "Brinquedoteca: espaço interdisciplinar de ludicidade, arte e aprendizagem".

Ressalta-se que o projeto visa ao desenvolvimento de habilidades que levem 0 aluno/monitor a desempenhar funções necessárias ao funcionamento da brinquedoteca, tais como o laboratório de ensino, considerando a organização e a manutenção deste espaço de aprendizagem. Ademais, garante a interação com a comunidade beneficiária, além da produção de materiais necessários ao desenvolvimento de atividades, como a contação de histórias e 0 acolhimento de crianças e outros usuários.

Do plano de trabalho "Dramatizações e contação de histórias infantis", executado em 2018, dentre as atividades de extensão da Brinquedoteca do CAFS, emergiu o interesse em trabalhar a atividade de contação de história em uma perspectiva da educação que reconhece a importância da discussão em torno das relações etnorraciais na Educação Infantil, mediante a formulação do plano de trabalho intitulado "Pretagogia: a contação de história na perspectiva etnorracial nas atividades da Brinquedoteca do CAFS". Nesse momento, considera-se relevante recordar que da população de Floriano, um percentual considerável de habitantes se declara negro, especificamente $78,6 \%{ }^{1}$ da população, segundo dados da PNAD de 2016.

A discussão que se segue tem como marco orientador a compreensão da criança como um ser de direitos, em desenvolvimento, que esteja numa faixa etária entre 0 e 12 anos, conforme estabelece 0 Estatuto da Criança e do Adolescente (ECA) (Brasil,1990). 0 compartilhar sobre 0 entendimento acerca da criança presente na legislação brasileira se faz necessário neste relato, uma vez que nossas ações na referida Brinquedoteca incorporam as concepções acerca da infância que não são estáticas ou heterogêneas, e dizem respeito à garantia de bem-estar destas.

\section{METODOLOGIA}

Este relato levou em consideração em sua construção os princípios inerentes à abordagem qualitativa em pesquisa que, segundo Lakatos e Marconi (2009), tem por preocupação a análise e interpretação de aspectos mais profundos, detendo-se sobre a descrição com vista a apreender a complexidade do comportamento humano. Esta abordagem segundo os autores fornece análises mais detalhadas sobre investigações, tendências de comportamento, hábitos e atitudes, contribuindo decisivamente para desvelar a realidade educacional. 
A experiência relatada teve como lócus a Brinquedoteca Mundo Encantado e quatro escolas da rede municipal de educação de Floriano, cujos participantes foram os alunos devidamente matriculados nas referidas instituições, na faixa etária de 3 a 5 anos de idade.

\section{RELAÇÕES ETNORRACIAIS: A CONSTRUÇÃO DA IDENTIDADE NEGRA DA CRIANÇA}

Para iniciar esta discussão, consideramos relevante recordar que o conceito raça encontra-se ultrapassado, tendo em vista 0 entendimento de que não existe necessidade de diferenciação entre os seres humanos nesse sentido, e muito menos nos caberia uma classificação em "raças". Portanto, a denominação mais apropriada seria "etnia". Gomes (2005), afirma que a palavra "raça" seria um termo amplamente utilizado para designar a subjetividade de pessoas com pele negra, a partir de uma análise fenotípica, com a intenção de subalternizar a etnia negra e pessoas retintas ${ }^{2}$.

Discutir identidade, sobretudo sua construção, requer aprofundamento no entendimento no que se diz respeito ao ser "criança" e como são estabelecidas suas relações sociais. Para Rios (2011), a identidade é uma construção multirreferencial, definida por processos complexos de significação socialmente determinados por experiências vivenciadas pelo indivíduo. Portanto, a identidade não é uma positividade, tampouco um absoluto que se encerra em si mesmo, e sim uma relação.

Em convergência, encontra-se a perspectiva de Goffman (1975), que dentro da sua teoria sobre 0 estigma da identidade pessoal, trata sobre 0 multirreferencialismo cultural, destacando 0 sujeito como capaz de moldar suas ações com base nas expectativas dos outros. Estas seriam uma forma de controle social, no qual se seleciona de acordo com os princípios da sociedade 0 que se é adequado ao pensamento hegemônico da época e o que é tido como anormal.

Autores como Kramer (2007) ressaltam que as visões sobre a infância são construídas dentro do fator social e histórico do meio em que elas se inserem. A inserção concreta das crianças e seus papéis variam conforme os modos de organização da sociedade. Desse modo, a ideia de infância não permanece estática, sendo modificada constantemente, apresentando variações de uma sociedade para outra, inclusive quanto à sua duração. Assim, crianças constituem-se como sujeitos sociais e históricos, marcados pelas contradições das sociedades em que estão inseridas. A criança não se resume a ser alguém que não é, mas o que se tornará (o adulto, no dia em que deixar de ser criança) (Kramer, 2007).

Nessa direção, Kramer (2007) nos alerta de que normalmente vivemos em uma linha tênue, onde em um lado temos grandes discussões e considerações sobre a criança e em outro encontramos inúmeras dificuldades em lidar com o público infantil. Ainda se caracteriza a criança como um ser não social, que por sua vez, ainda é um ser a-histórico, apolítico e acrítico, que não possui produtividade como um adulto. As imagens utilizadas em instrumentos didáticos de muitas escolas no Brasil, apesar do título de país miscigenado, remetem em sua maioria a características fenotípicas eurocentradas da criança, ou seja, loiras de cabelos lisos (Courtney, 1990).

Na formulação deste projeto, quando sentimos a necessidade de pesquisar quais estórias infantis comumente são contadas para as crianças, com sentido de "moral da estória", pudemos observar que são sempre colocadas como protagonistas mulheres meigas e doces, que apresentam como características pele clara, cabelos loiros, quando não, bem pretos, porém lisos escorridos, olhos claros, corpo esbelto e de uma beleza inimaginável. Tal cenário converge com o pensamento de Bento (2011) de que as ilustrações presentes nos ambientes escolares inferem que ainda existe uma hierarquia racial ancorada no padrão branco em detrimento do retinto, o que pode não oferecer parâmetros de construção de identidade valorizada à criança negra e também, de modo nocivo, ensinar à criança branca, equivocadamente, que ela compõe um grupo superior.

Nessa discussão, recordamos Fanon (1983), quando este analisa com base na tese "pele negra, 


\section{PERSPECTIVA AFROCENTRADA NAS CONTAÇ̃̃ES DE HISTÓRIA NA BRINQUEDOTECA DO CAFS: FORTALECIMENTO DA AUTOESTIMA E IDENTIDADE NEGRA DE CRIANÇAS}

máscaras brancas", que a postura de uma criança em se identificar como branca e desconhecer-se como negra foi socialmente construída a partir de suas experiências na sociedade. Dessa forma surge o racismo cordial ou preconceito velado que permeia nossa sociedade que, de modo peculiar, reconhece a existência do racismo sem que as pessoas se assumam como racistas (Gomes, 2005).

0 cenário retratado nesta discussão só torna mais explícita a disparidade social existente entre as etnias, ainda mais quando se pensa em um desenvolvimento típico de uma criança negra, sua construção identitária e a formação da autoestima desta, lembrando que esse caso se assevera a depender do quanto retinta essa criança possa ser.

Subsidiada em dados assustadores, a Lei 10.639/03 que trata dos desdobramentos das Diretrizes Curriculares Nacionais Para a Educação das Relações Etnorraciais e para 0 Ensino de História e Cultura Afro-Brasileira e Africana, reúne ${ }^{3}$ índices que ilustram que as pessoas negras no Brasil estudam em média 4,2 anos, enquanto pessoas brancas estudam 6,2 anos. Na faixa de $14 \mathrm{e}$ 15 anos, há um total de $12 \%$ a mais de negros analfabetos em relação aos brancos. Cerca de $15 \%$ das 72 crianças brancas de 10 a 14 anos de idade estão inseridas de algum modo no mundo de trabalho, enquanto o percentual de crianças negras inseridas neste mesmo mundo do trabalho é de $40 \%$.

Ao refletirmos sobre o referido cenário, verifica-se que políticas públicas educacionais relativas às relações etnorraciais, como a meta de reeducação da população sobre a conscientização ao racismo estrutural, constitui, certamente, uma alternativa. Gomes (2005) compartilha desse pensamento, quando afirma que a escola é um espaço primordial para a promoção de conhecimentos e quebras de paradigmas arcaicos acerca das relações étnicas, sendo a ludicidade uma ferramenta para a desconstrução da subalternização do povo negro, produto da formação histórica da população brasileira. A ação da escola se estende não somente aos alunos, mas deve se direcionar aos próprios educadores e outros adultos que vivenciaram outro tipo de formação.

Não poderíamos deixar de recordar ao final desta discussão que colocamos na educação a esperança de ressarcimento da dívida histórica que os negros carregam desde o fim do processo de escravidão, pois nos alinhamos à perspectiva de Munanga (2005), que concebe o lugar do resgate da memória coletiva e da história da comunidade negra como algo que não interessa apenas aos alunos de ascendência negra. Interessa também aos alunos de outras ascendências étnicas, principalmente branca, pois ao receber uma educação envenenada pelos preconceitos, eles também tiveram suas estruturas psíquicas afetadas.

Recorda-se, ainda, que esta memória não pertence somente aos negros. Ela pertence a todos, tendo em vista que a cultura da qual nos alimentamos quotidianamente é fruto de todos os segmentos étnicos. Apesar das condições desiguais nas quais se desenvolvem, contribuíram cada um de seu modo na formação da riqueza econômica, social e da identidade nacional.

\section{RESULTADOS E DISCUSSÃO}

A experiência aqui descrita foi desenvolvida como parte de um projeto maior, intitulado "Brinquedoteca: espaço interdisciplinar de ludicidade, arte e aprendizagem". Dentro deste projeto maior se encontra o plano de trabalho que relatamos, no caso, "Dramatização e contação de histórias infantis". Na execução do referido plano emergiu o interesse em trabalhar a atividade de contação de histórias que de algum modo promovesse a discussão em torno das relações etnorraciais desde a Educação infantil, tendo em vista que essa discussão tem sido marginal em muitas escolas brasileiras, apesar das exigências legais de se garantir a mesma nos diferentes espaços sociais, dentre eles a escola.

A execução do referido plano de trabalho se fundamentou em posicionamentos como os de Riglisk (2012), de que todas as pessoas, sem distinção de idade, gostam de ouvir histórias. Estas, 
desde os tempos remotos, têm contribuído para a formação da memória coletiva de uma comunidade, pois por meio do ato de contar histórias na forma de contos, lendas e mitos, transmitem-se as raízes culturais de um povo. A autora aponta também que nos dias atuais a arte de contar histórias ganhou conotação e espaço maior, tornando-se valioso instrumento no processo educativo, devido ao seu aspecto lúdico, e tendo como principal objetivo divertir e estimular a imaginação das crianças.

Também tomamos por suporte o pensamento de Kuhlmann Jr. (1998), de que as crianças participam das relações sociais, sendo este processo não exclusivamente psicológico, mas social, cultural e histórico. As crianças buscam essa participação, apropriam-se de valores e comportamentos próprios de seu tempo e lugar, porque as relações sociais são parte integrante de suas vidas e de seu desenvolvimento. Dessa forma, corroborando com a lei 10.639/03 que torna obrigatório 0 ensino da história e cultura afro-brasileira e africana em todas as escolas públicas e particulares, do Ensino Fundamental até o Ensino Médio, a contação de histórias assume caráter de recurso formativo a ser utilizado pelo professor no processo de educação das relações etnorraciais, com o objetivo de combater o racismo, a injúria e o preconceito racial.

Embora a legislação brasileira assegure alguns direitos à criança, como o direito ao lazer, ao esporte, à cultura e à educação (Brasil, 1988), e inserido entre eles o brincar, devido a questões ligadas às contingências da sociedade contemporânea, esses mesmos direitos têm sido subtraídos da vida de milhares de crianças em nosso país. Frente a essa realidade, percebeu-se que momentos de contação de histórias com foco nas relações etnorraciais, como os que foram realizados em 2018, funcionaram como ferramenta de combate ao preconceito e ao racismo junto às crianças da cidade de Floriano. Mediada pelo enredo e pela situação-problema, coloca-se na prática da contação de história a possibilidade de a criança fazer uma autorreflexão em relação ao meio em que vive, posicionando-se dentro do processo de imaginação como personagem principal da história.

Assim como Ferrarini, Valore e Camargo (2012), compreendemos que a discussão sobre a identidade racial integra o processo de reflexão sobre as múltiplas determinações que impactam a formação da identidade como um todo, bem como na configuração da subjetividade. Nessa direção, busca-se a apropriação da objetividade de forma menos alienada com vistas à participação ativa do sujeito enquanto ser histórico nesse processo identitário.

\section{Confecção de recursos de contação de histórias}

Para que os momentos de contação se efetivassem, foram utilizados os recursos da brinquedoteca confeccionados pelos alunos monitores do CAFS destinados aos momentos de contação de histórias. Em geral os recursos produzidos têm o intuito de prender a atenção dos ouvintes através dos jogos de cores e divertimento da história contada. 
Foto 1 - Confecção da "Menina Bonita do Laço de Fita" Fonte: Acervo fotográfico da Brinquedoteca (2018).

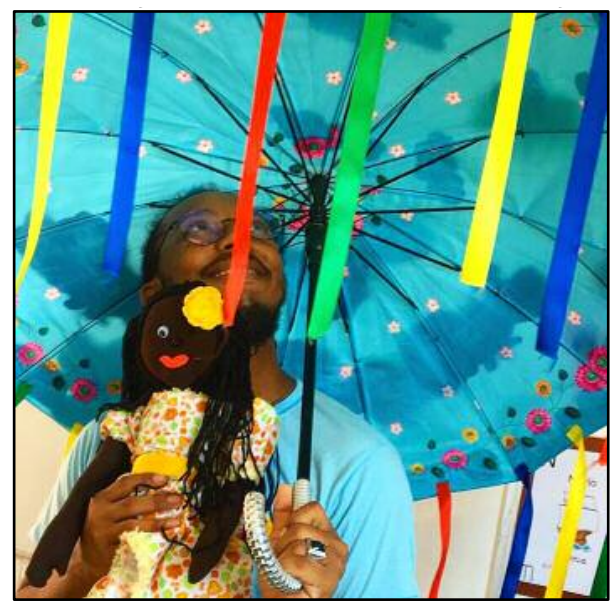

Foto 2 - Recursos de "O Pássaros de Todas de Todas as cores" Fonte: Acervo fotográfico da Brinquedoteca (2018).

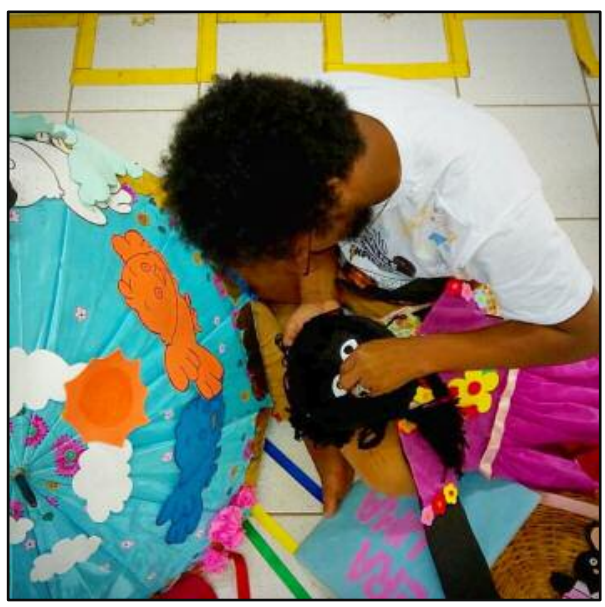

0 processo de confecção de material foi essencial ao projeto, pois envolveu um estudo delicado sobre materiais didáticos e recursos pedagógicos. 0 objetivo foi entender 0 método que se utilizaria na prática das contações, no que diz respeito às intervenções entre 0 material físico dentro fala do contador de história, e de que forma esses recursos poderiam auxiliar no processo de compreensão da história pela criança. 


\section{Nossos momentos de contação de histórias}

As práticas de contação de histórias, bem como outras atividades, acontecem por meio de agendamento do espaço da brinquedoteca, ou nos momentos em que ocorre a itinerância da Brinquedoteca em escolas públicas municipais de Floriano. No que tange à proposta do trabalho relatada, na contação de histórias infantis etnorraciais nas escolas visitadas foram selecionadas as histórias "A menina bonita do laço de fita" e "0 pássaro de todas as cores". Estas histórias foram contadas nas seguintes escolas e creches: Centro Educacional Solimar Alencar Lima, Creche Municipal Binú Leão, Escola Municipal Marenice Attem e Escola Municipal Raimundinha Carvalho. Os momentos de contação foram registrados conforme as imagens abaixo:

Foto 3 - Contação de história "O pássaro de todas as cores" Fonte: Acervo fotográfico da Brinquedoteca (2018).

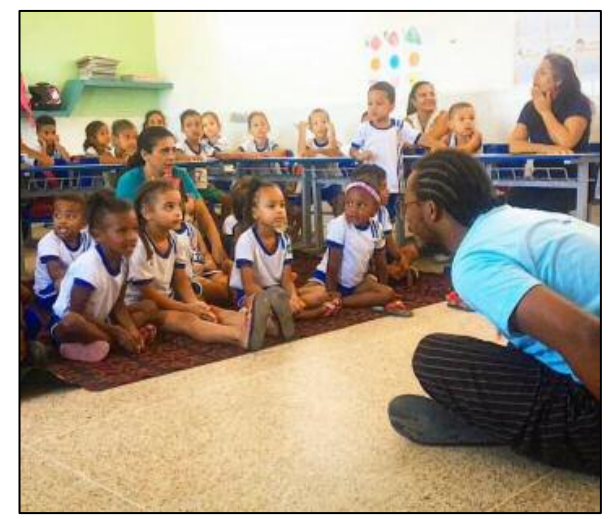

Foto 4 - Contação de história "A menina bonita do laço de fita" Fonte: Acervo fotográfico da Brinquedoteca (2018).

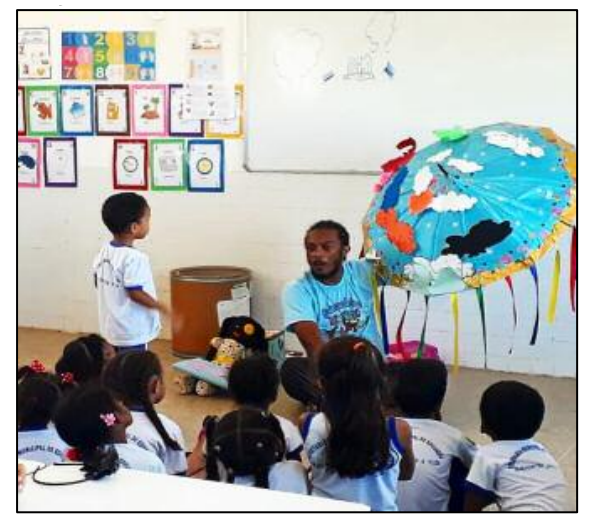

Nos momentos de contação, percebeu-se que as crianças identificavam nas histórias contadas a existência de personagens que se pareciam fisicamente com elas (cor de pele e cabelo, por exemplo). Isso ficou evidente em falas das crianças, tais como "meu cabelo é lindo igual o da menina do 
laço de fita", "o coelho é bonito, e a menina também é bonita", "o passarinho tem que gostar da cor dele, porque ele é lindo", "o passarinho tem a cor igual a minha" e "você é branca de neve, eu sou a menina bonita do laço de fita e ela é a Moana". As histórias selecionadas apresentavam personagens brancas e negras, o que permitiu, no momento de reflexão coletiva sobre a história, que uma grande parte das crianças identificasse a presença das personagens negras e ainda atribuísse a elas beleza e outras características positivas.

Tendo em vista que o processo de construção da identidade é um processo delicado e contínuo, entende-se que a elevação da autoestima da criança e aceitação de sua etnia e traços fenotípicos é um trabalho complexo, que se complexifica com ações como as realizadas no projeto em questão e relatadas neste trabalho, uma vez que almeja 0 fortalecimento da autoestima de crianças negras mediante uma perspectiva afrocentrada assentada na ludicidade. Ressalta-se que a eficiência do mesmo tem se mostrado explicita no contato que realizamos posteriormente com os educadores dessas crianças, momento em que se confirma a contação como uma ferramenta que tem despertado muitas reflexões sobre a identidade de crianças negras, sobretudo aquelas que vivenciaram conosco esta experiência.

\section{CONSIDERAÇÕES FINAIS}

Avaliamos que nas contações de histórias em que se apresentam personagens negros em posição de destaque, é conferida centralidade à perspectiva afrocentrada e de valorização da cultura popular negra brasileira. Isso constitui um grande esforço no sentido de problematizar as relações étnico-raciais no país, pois é notório que os personagens brancos em sua grande maioria são colocados em situações de privilégio em comparação aos personagens negros, assumindo quase sempre 0 protagonismo das histórias sem maiores preocupações com as desigualdades geradas e reproduzidas com a apresentação de cenários como este.

Assim, as ações de extensão desenvolvidas na brinquedoteca relativas à contação de histórias, fundamentadas na perspectiva etnorracial, possibilitaram aos alunos-monitores, na função de brinquedistas do CAFS, vivenciarem outros espaços educativos além da Brinquedoteca. Ademais, os alunos-monitores puderam aprender a desenvolver planejamento de atividades que envolveram contato com outras instituições de ensino e públicos distintos, além de permitir um melhor desempenho diante do público atendido e da plateia ouvinte das histórias contadas. Por fim, a prática na Brinquedoteca possibilitou aos bolsistas a conquista progressiva acerca de uma compreensão mais complexa sobre a infância. De que a criança enquanto sujeito em processo de aceitação da sua cultura e grupo étnico, pode ter ganhos ilimitados para a construção de sua identidade, como nos momentos de contação de histórias. Este proporcionaram a elas práticas em que foram apresentadas e visualizadas personagens em um sentido etnorracial, e que puderam contribuir com a dinâmica relativa ao processo de construção de sua identidade.

\section{REFERÊNCIAS}

Bento, M. A. S. (2011). A identidade racial em crianças pequenas. In: M. A. S. Bento (Org.), Educação infantil, igualdade racial e diversidade: aspectos políticos, jurídicos e conceituais (pp. 98-117). São Paulo: Centro de Estudos das Relações de Trabalho e Desigualdades - CEERT.

Constituição da República Federativa do Brasil. (1988). Brasília: Senado. Recuperado a partir de http://www.planalto.gov.br/ccivil_03/constituicao/constituicao.htm

Courtney, R. (1990). Drama e inteligência: uma teoria cognitiva. Montreal. Imprensa da Universidade de McGill-Queen.

Fanon, F. (1983). Pele negra, máscaras brancas. (A. Caldas, Trad.). Rio de Janeiro: Fator. 
Ferrarini, N. L.; Valore, L. A. \& Camargo, D. de. (2012). Políticas afirmativas e construção da identidade em universitários afrobrasileiros. International Journal of Developmental and Educational Psychology, INFAD Revista de Psicología, 2(1), 203-210.

Goffman, E. (1975). A representação do eu na vida cotidiana. Petrópolis: Vozes.

Gomes, N. L. (2005). Alguns termos e conceitos presentes no debate sobre relações raciais no Brasil: uma breve discussão. (pp. 39-62). In: Educação anti-racista: caminhos abertos pela Lei Federal $n^{\circ}$ 10.639/03. Brasília: MEC/SECAD.

Kramer, S. (2007). A infância e sua singularidade. In: J. Beauchamp, S. D. Rangel \& A. R. Nascimento (Orgs.), Ensino fundamental de nove anos: orientações para a inclusão da criança de seis anos de idade (pp. 13-24). Brasília: Ministério da Educação, Secretaria de Educação Básica.

Kuhlmann Jr, M. (1998). Infância e educação infantil: uma abordagem histórica. Porto Alegre: Mediação.

Lakatos, E. M. \& Marconi, M. de A.(2009). Técnica de Pesquisa. 6a ed. São Paulo: Atlas.

Lei no 8.069 de 13 de julho de 1990. Dispõe sobre o Estatuto da Criança e do Adolescente e dá outras providências. Recuperado a partir de http://www.planalto.gov.br/ccivil-_03/leis/L8069.htm

Ministério da Educação. (2006). Orientações e ações para a educação das relações étnico-raciais. Brasília: MEC/SECAD.

Munanga, K. (2005). Superando o racismo na escola. (2a ed.). Brasília: MEC/ SECAD- Secretaria da Educação Continuada, Alfabetização e Diversidade.

Riglisk, A. S. (2012). Contribuições da contação de histórias no desenvolvimento das linguagens na infância. Repositório Institucional: UNIJUÍ. Recuperado a partir de: http://bibliodigital.unijui.edu.br:8080/xmlui/bitstream/handle/123456789/1619/TCC\%202012\% 20Adriane \%20S.\%20Rigliski.pdf?sequence $=1$

Rios, J. A. V. P. (2011). Ser e não ser, eis a questão! Identidades e discursos na escola. Salvador: Edufba.

Rossato, C. \& Gesser, V. (2011). A experiência da branquitude diante de conflitos raciais: estudos de realidades brasileiras e estadunidenses. In: E. Cavalleiro (Org.), Racismo e anti-racismo na educação. São Paulo: Selo Negro.

\section{NOTAS}

10 Instituto Brasileiro de Geografia e Estatística (IBGE), através da Pesquisa Nacional por Amostra de Domicílios (PNAD), que reúne informações sobre características demográficas e socioeconômicas da população, como sexo, idade, etnia, educação, trabalho e rendimento, e características dos domicílios, identificou no ano de 2016 que a população florianense apresenta (por autodeclaração) $71,4 \%$ de pessoas pardas, $21,4 \%$ de pessoas brancas e $7,2 \%$ pretos. Por fim o próprio IBGE reúne em grupos Étnicos (Negros, Brancos e Indígenas), e considera pretos e pardos como grupo étnico "negro", dando assim o total de $78,6 \%$ de pessoas negras em Floriano-PI.

2 "Retinto" diz respeito ao termo utilizado por grandes estudiosos das relações etnorraciais, dando um sentido de melanina mais acentuada sobre a pele, substituindo assim os termos "mais negro" e "menos negro".

3 Em 2013, dez anos após a aprovação da Lei 10.639/03, foi publicada a primeira pesquisa nacional sobre os desdobramentos das Diretrizes Curriculares Nacionais Para a Educação das Relações Étnico-raciais e para o Ensino de História e Cultura Afro-Brasileira e Africana, dando origem ao dossiê "Relações Étnico Raciais e práticas pedagógicas: resultados da pesquisa nacional Práticas Pedagógicas de trabalho com relações étnico-raciais na escola na perspectiva 
PERSPECTIVA AFROCENTRADA NAS CONTAÇÕES DE HISTÓRIA NA BRINQUEDOTECA DO CAFS:

FORTALECIMENTO DA AUTOESTIMA E IDENTIDADE NEGRA DE CRIANÇAS

da Lei 10.639/03". A pesquisa foi coordenada pelo Programa de Ações Afirmativas da UFMG e pelo Núcleo de Estudos e Pesquisas sobre Relações Étnico Raciais e Ações Afirmativas (NERA/CNPq, em parceria com pesquisadores (as) de vários NEABs, da SECADI/MEC e da UNESCO no Brasil. 